\title{
Flow characteristics at trapezoidal broad-crested side weir
}

\author{
Jaromír Ríha*, Zbyněk Zachoval \\ Brno University of Technology, Faculty of Civil Engineering, Institute of Water Structures, Veveři 331/95, 60200 Brno, Czech Republic. \\ ${ }^{*}$ Corresponding author. Tel.: +420 541147753. Fax:+420 541147752. E-mail: riha.j@fce.vutbr.cz
}

\begin{abstract}
Broad-crested side weirs have been the subject of numerous hydraulic studies; however, the flow field at the weir crest and in front of the weir in the approach channel still has not been fully described. Also, the discharge coefficient of broad-crested side weirs, whether slightly inclined towards the stream or lateral, still has yet to be clearly determined. Experimental research was carried out to describe the flow characteristics at low Froude numbers in the approach flow channel for various combinations of in- and overflow discharges. Three side weir types with different oblique angles were studied. Their flow characteristics and discharge coefficients were analyzed and assessed based on the results obtained from extensive measurements performed on a hydraulic model. The empirical relation between the angle of side weir obliqueness, Froude numbers in the up- and downstream channels, and the coefficient of obliqueness was derived.
\end{abstract}

Keywords: Broad-crested side weir; Experimental research; Flow characteristics; Hydraulics.

\section{INTRODUCTION}

Broad-crested side weirs are often used as lateral weirs on flood levees when serving as emergency spillways, located adjacent to the river or on setback levees. Due to their layout, weirs are usually parallel or slightly inclined toward the general flow direction. In the case of levees set back from the main channel, a low Froude number flow is common in the inundation area. In the following, rivers and also inundated floodplains are referred to as "channels". As the described research study addresses mainly weirs at river levees, the following factors were taken into account (Fig. 1):

- Oblique angle $\phi$ of side weir axis with respect to the principal flow direction typically exceeds $60^{\circ}$, so that angles of $60^{\circ}$, $75^{\circ}$ and $90^{\circ}$ were studied.

- Flow in the channel is subcritical at low Froude numbers.

- Non-submerged conditions are standard at levee spillways.

- Service vehicle traffic is accommodated on the levee crest. The longitudinal profile of the weir crest is thus trapezoidal with sloped sections typically featuring an incline of 1:4. Due to the trapezoidal shape of embankment levees, the cross section of the weir is also trapezoidal, with slopes typically of 1:2 or lower. The weir crest was assumed to be smooth in this study.

In this study the greatest attention is paid to the analysis of the flow conditions at the weir crest and the determination of the weir obliqueness correction factor.

\section{LITERATURE REVIEW}

When studying the hydraulic conditions at side weirs, onedimensional (1D) flow in the approach channel is traditionally assumed (Bos, 1989; Castro-Orgaz and Hager, 2012; De Marchi, 1934; Hager, 1987; Honar and Javan, 2007). The governing equations are derived using the constant specific energy concept, and the momentum approach (Rosier, 2007). The constant specific energy concept for side weirs was introduced by De Marchi (1934), who considered a prismatic rectangular channel with subcritical flow. For a non-prismatic channel, or if significant energy losses occur along the weir, the energy line and water level should be determined using an appropriate numerical method (Bos, 1989). The total overflow discharge should be determined from partial discharges at the computational reaches along the lateral weir. Two approaches are avail- able to obtain the discharge coefficient. The first employs a known discharge coefficient for standard broad-crested weirs (Bos, 1989; Hager, 1987; ISO 8333, 1985; ISO 4362, 1999). For side weirs this overflow discharge is reduced by a correction factor due to weir obliqueness (Bos, 1989; Honar and Javan, 2007). In the second approach the discharge coefficient is derived from flow conditions in the channel for the specific type of lateral weir (Aghayari et al., 2009; Borghei et al., 1999; Frazer, 1957; Hager, 1987; Honar and Javan, 2007; Ranga Raju et al., 1979; Rosier, 2007; Singh et al., 1994; Subramanya and Awasthy, 1972; Swamee et al., 1994). This correction factor is usually introduced for a prismatic channel and a specific weir type and arrangement.

The formulae for the discharge coefficient are derived from both dimensional analysis and the velocity field at the weir crest. The most relevant factors are the approach flow angle (Rosier, 2007) and weir obliqueness (Hager, 1987; KabiriSamani et al., 2010; Subramanya and Awasthy, 1972). Using dimensional analysis, a series of dimensionless parameters influencing the discharge coefficient are found; however, only a few of these have been experimentally considered.

The purpose of this study is to contribute to the investigation of the effect of side weir obliqueness on the flow field in the approach channel and on the discharge coefficient of the weir and its sections.

\section{THEORETICAL BACKGROUND}

The total overflow discharge $Q_{p}$ for a trapezoidal weir is

$Q_{p}=Q_{p T u}+Q_{p p}+Q_{p T d}$

where $Q_{p p}$ is the discharge over the horizontal weir crest section, and $Q_{P T u}$ and $Q_{p T d}$ are overflow discharges over the inclined up- and downstream sections.

For a side trapezoidal broad-crested weir with a trapezoidal weir profile (ISO 4362, 1999; ISO 8333, 1985)

$$
\begin{aligned}
& Q_{p}=\left(\frac{2}{3}\right)^{3 / 2} C_{D} C_{\nu} C_{\phi} b_{p} \sqrt{g} h_{p}^{3 / 2} \\
& +\left(\frac{4}{5}\right)^{5 / 2} C_{D T} C_{\nu} C_{\phi} \sqrt{\frac{g}{2}} \operatorname{tg}\left(\frac{\beta}{2}\right) h_{p}^{5 / 2}
\end{aligned}
$$


(a)

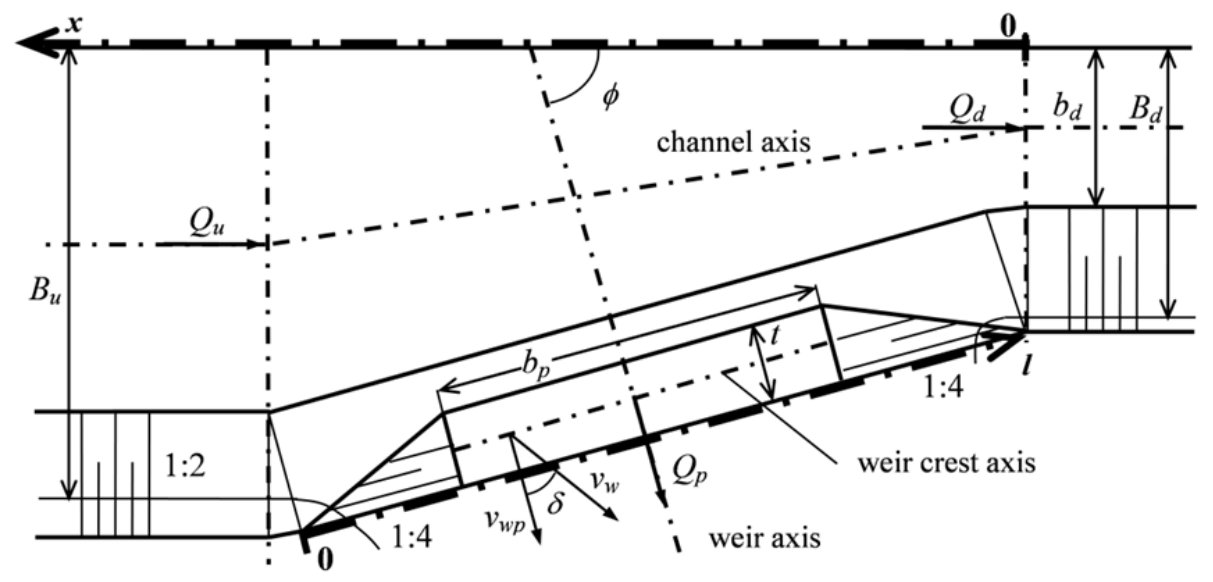

(b)

upstream profile

downstream profile

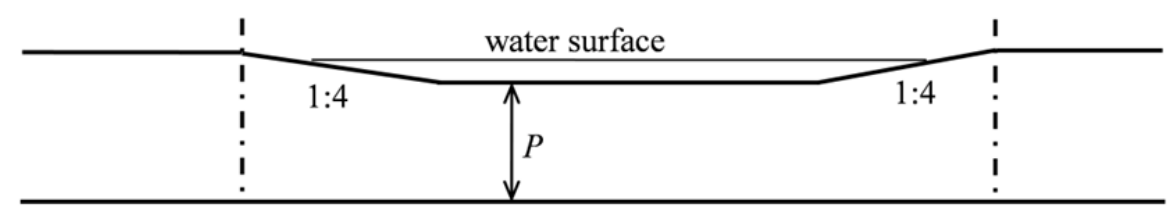

(c)

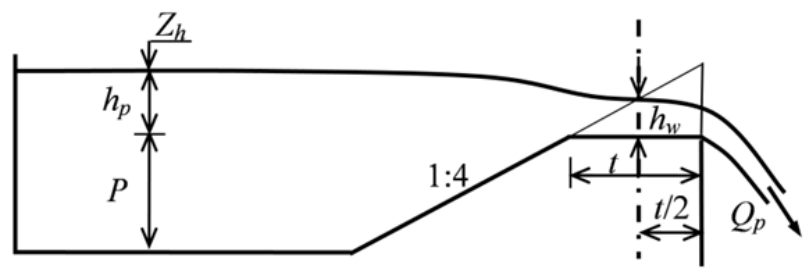

Fig. 1. Flow over trapezoidal side weir (a) top view; (b) side view; (c) cross-section.

Here $C_{D}$ and $C_{D T}$ are the discharge coefficients of frontal rectangular and V-shaped broad-crested weirs, $C_{v}$ is the approach flow velocity coefficient, $C_{\phi}$ the weir obliqueness correction factor (Bos, 1989; Honar and Javan, 2007) expressing losses due to a change in flow direction, $b_{p}$ is the weir width, $g$ is gravitational acceleration, $h_{p}$ the overflow head and $\beta$ the notch angle. Coefficients $C_{D}$ and $C_{D T}$ express the influence of the geometry and roughness of a frontal weir and depend on the dimensionless parameters $h_{p} / P, h_{p} / t, 1 / T$ and $h_{p} / k_{s}$, where $P$ is weir height, $t$ the weir crest length in the flow direction, $1 / T$ the upstream levee slope and $k_{s}$ Nikuradse's equivalent sand roughness height.

With $\mathrm{Fr}_{u}$ and $\mathrm{Fr}_{d}$ as the Froude numbers in the up- and downstream channel and $\phi$ as the oblique angle (Fig. 1) the weir obliqueness correction factor $C_{\phi}$ is

$C_{\phi}=\mathrm{f}\left\{\frac{\mathrm{Fr}_{d}}{\mathrm{Fr}_{u}}, \cos \phi\right\}$.

In Eq. (3) the Froude number expressing the flow regime in the channel is defined as
$\operatorname{Fr}=\frac{Q \sqrt{B}}{\sqrt{g A^{3}}}$

where $A$ is the cross-sectional area of the channel and $B$ the width of the water surface. For lowland inundated areas with a side weir in a levee $h_{p} / B<0.1$ (Bos, 1989) the flow is subcritical if $\mathrm{Fr}_{u}<0.15$ even under extreme flood discharges. Consequently, the approach flow velocity head is negligible and the water level in the channel is practically parallel and linear to the weir crest (Frazer, 1957), and therefore $C_{v} \approx 1$ and $h_{p} \approx$ const. Experimental research was performed to describe the flow characteristics at the weir crest and to determine the weir obliqueness correction factor.

\section{EXPERIMENTS}

A model of a trapezoidal broad-crested side weir with a trapezoidal profile was set up at the Institute of Water Structures, the Laboratory of Water Management Research, at the Faculty of Civil Engineering, Brno University of Technology (Fig. 2). Three weir layouts with oblique angles of $\phi=90^{\circ}, 75^{\circ}, 60^{\circ}$ were studied (Fig. 1). 
The model was located in a flume of length $17.4 \mathrm{~m}$, depth $0.62 \mathrm{~m}$ and width $3.50 \mathrm{~m}$. Its upstream face was inclined with the same slope of 1:2 as the right levee upstream face. The left bank of the channel was vertical. The inclined sections of the weir crest were made as ramps of 1:4 slope. The length of the horizontal weir crest section was $b_{p}=1.50 \mathrm{~m}$, the length of the weir in the direction of overflow was $t=0.2 \mathrm{~m}$ and the weir height was $P=0.313 \mathrm{~m}$. The channel bottom was horizontal, and the width of the downstream channel bottom was $b_{d}=1.00 \mathrm{~m}$ (Fig. 1). The Manning roughness coefficient of the channel was $n=0.017 \mathrm{~s} / \mathrm{m}^{1 / 3}$, and $n=0.011 \mathrm{~s} / \mathrm{m}^{1 / 3}$ for the weir crest. The model was designed with Froude similitude (Novak and Ćábelka, 1981).

The length of the upstream channel ensured fully-developed flow with approximately uniform velocity distribution at the cross section upstream of the weir. The appropriate length of $12 \mathrm{~m}$ for the upstream reach was verified in the design phase using a 2D shallow flow numerical model. Discharge $Q_{u}$ was adjusted using a Thomson weir, while discharge $Q_{d}$ was determined using a calibrated multi-slit weir with an adjustable crest level, which enabled the setting of a downstream water level.
The flow over the side weir involved free flow conditions; the critical depth occurred on the weir crest. A movable cover on the lateral flume installed along the weir crest downstream of the side weir enabled the division and measurement of the overflow discharge in $0.100 \mathrm{~m}$ portions along the weir crest. The measurement of the specific overflow discharge along the weir crest was performed by gradually covering the remaining $0.1 \mathrm{~m}$ sections of the lateral flume.

For each $\phi$ several discharge conditions were studied. These are summarized together with $h_{p}$ in Table 1 . There were no measurements for $\phi=60^{\circ}$ and $Q_{d}=0 \mathrm{~m}^{3} / \mathrm{s}$ as in this case the flow is in the transitional zone (turbulent flow is not fullydeveloped), which does not correspond to Froude similarity (Novak and Čábelka, 1981).

The water level was measured by an ultrasound probe at the rectangular grid located in front of the side weir and also along the axis of the approach channel for all geometrical and discharge scenarios. 2D velocity field measurement (longitudinal and transversal components) was conducted by an UVP Monitor, model XW-PSi, while streamlines were depicted using floating markers (silk thread) and dye tracer.

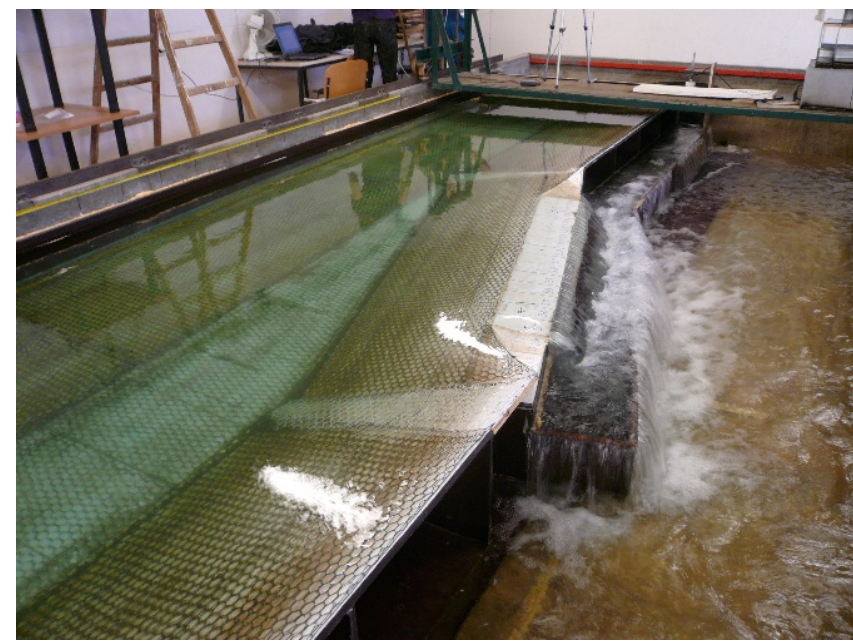

(a)

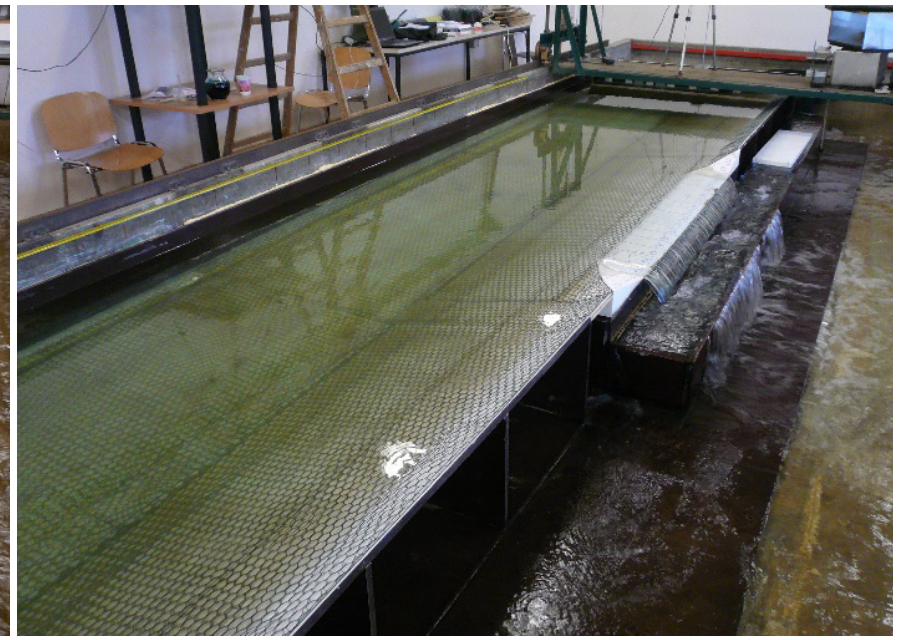

(b)

Fig. 2. Example of model layout, $\phi=75^{\circ}$ (a), $90^{\circ}$ (b).

Table 1. Average overflow head $h_{p}(\mathrm{~m})$ for discharge and oblique angle variants.

\begin{tabular}{|c|c|c|c|c|c|}
\hline \multirow{3}{*}{$\phi\left({ }^{\circ}\right)$} & $Q_{p}\left(\mathrm{~m}^{3} / \mathrm{s}\right)$ & \multicolumn{4}{|c|}{$Q_{d}\left(\mathrm{~m}^{3} / \mathrm{s}\right)$} \\
\cline { 2 - 6 } & 0.020 & 0.000 & 0.020 & 0.040 & 0.060 \\
\hline \multirow{4}{*}{90} & 0.030 & 0.0514 & 0.0406 & 0.0414 & 0.0426 \\
\cline { 2 - 6 } & 0.040 & 0.0618 & 0.0528 & 0.0540 & 0.0553 \\
\cline { 2 - 6 } & 0.050 & 0.0720 & 0.0637 & 0.0649 & 0.0667 \\
\cline { 2 - 6 } & 0.060 & 0.0801 & 0.0737 & 0.0752 & 0.0771 \\
\hline \multirow{4}{*}{75} & 0.020 & 0.0397 & 0.0826 & 0.0843 & 0.0871 \\
\cline { 2 - 6 } & 0.030 & 0.0515 & 0.0533 & 0.0545 & 0.0429 \\
\cline { 2 - 6 } & 0.040 & 0.0618 & 0.0637 & 0.0652 & 0.0653 \\
\cline { 2 - 6 } & 0.050 & 0.0794 & 0.0732 & 0.0752 & 0.0766 \\
\hline \multirow{5}{*}{60} & 0.060 & & 0.0821 & 0.0841 & 0.0861 \\
\cline { 2 - 6 } & 0.020 & & 0.0414 & 0.0422 & 0.0429 \\
\cline { 2 - 6 } & 0.030 & & 0.0533 & 0.0543 & 0.0548 \\
\cline { 2 - 6 } & 0.040 & & 0.0737 & 0.0652 & 0.0662 \\
\cline { 2 - 6 } & 0.050 & & 0.0821 & 0.0747 & 0.0756 \\
\hline
\end{tabular}




\section{EXPERIMENTAL RESULTS}

\section{Flow in front of weir}

The velocity measurements in front of the side weir showed two flow zones for $Q_{u}>Q_{d}$, namely the channel zone and the weir zone. These zones are separated by a boundary (dotted line in Fig. 3) at which vortices with approximately vertical axes develop. The boundary is not sharp but rather appears to be a dividing zone at which mutual mixing exists. This effect is caused by the approximately constant magnitude of the velocity vector at the overflow zone and the decelerated velocity in the channel zone along the side weir. It was found that the change in the velocity head in the overflow zone along the weir is practically negligible and that the maximum relative difference does not exceed $2 \%$. The boundary between the two zones determined from the velocity field measurements is shown in Fig. 3.

\section{Overflow head}

To determine the overflow head $h_{p}$ along the weir, the difference between the water level $Z_{h}$ along the channel axis and the water level at the downstream weir profile $(x=0)$ was analyzed.
When compared with the measurement accuracy $( \pm 0.001 \mathrm{~m})$, the $Z_{h}$ remains practically constant. More significant differences were only identified at the locations of vortices at the separation line between the two flow zones. Therefore, $Z_{h}$ and $h_{p}$ are considered constant.

\section{Flow over weir crest}

From the measurements, the velocity components, the angle $\delta$ and the water depth $h_{w}$ (Fig. 1) along the weir crest were assessed. The angle $\delta$ is shown for selected scenarios in Fig. 4. Note that $\delta$ decreases in the downstream direction along the weir crest axis and is even negative along the downstream edge. These negative values were also identified by Rosier (2007). Inclined sections of the weir crest significantly influence $\delta$ near the toes. Similar behaviour was also identified by Stilmant et al. (2013). It was observed that for smaller $\phi$ the differences in $\delta$ along the crest are less significant. The mean $\delta$ values obtained from our measurements are about $10 \%$ smaller than those of Hager (1987). The $\delta$ values calculated according to Subramanya and Awasthy (1972) are some 50\% smaller due to the different geometry of the channel and the weir.

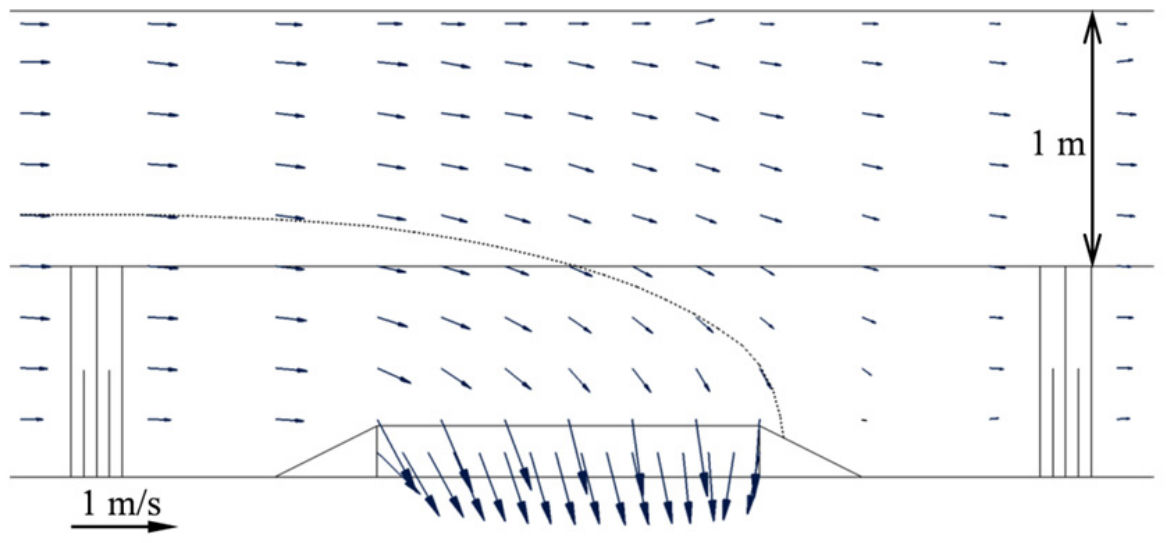

Fig. 3. Example of depth-averaged velocity field with boundary between channel and weir zone (dotted line) for $\phi=90^{\circ}, Q_{d}=0.060 \mathrm{~m}^{3} / \mathrm{s}$, $Q_{p}=0.060 \mathrm{~m}^{3} / \mathrm{s}$.

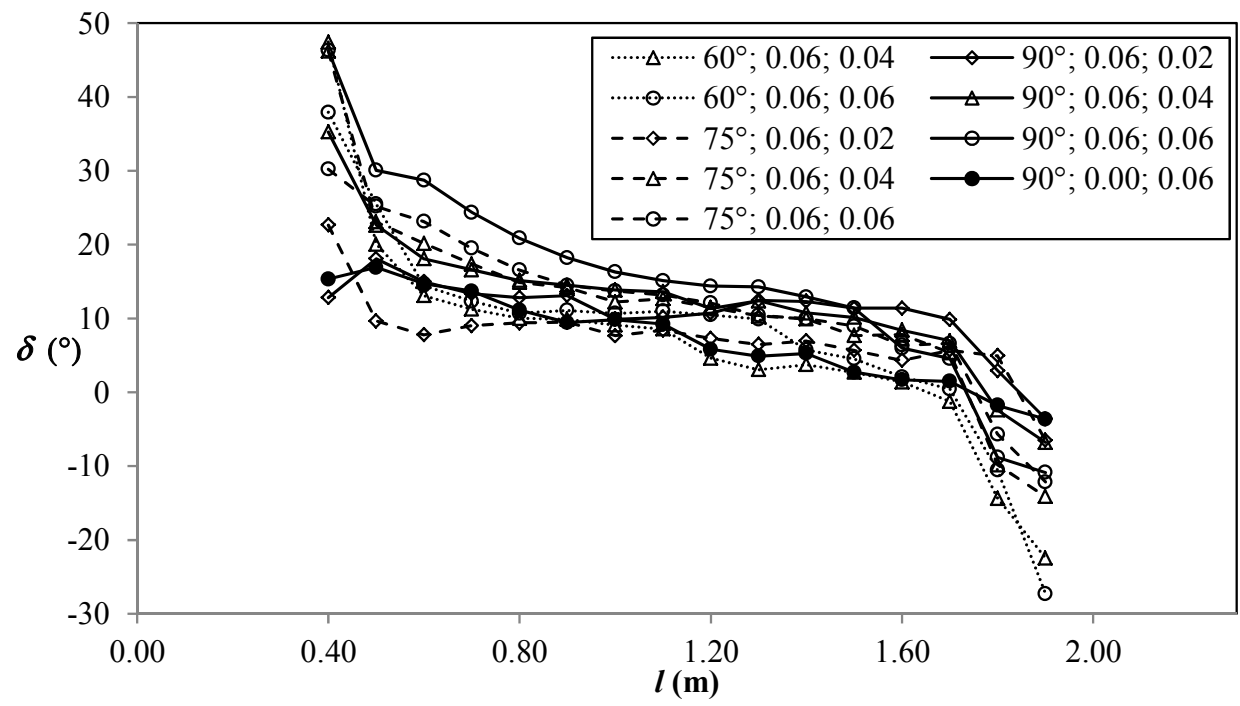

Fig. 4. Velocity angle $\delta$ along weir crest axis (legend: $\phi ; Q_{d} ; Q_{p}$ ). 
For individual oblique angles $\phi, h_{w}$ along the longitudinal weir axis was related to the mean depth $h_{w a}$. Figures 5 to 7 show that $h_{w}$ in the central part of the horizontal weir crest section is approximately constant for all $\phi$ values and is slightly lower at the upstream and higher at the downstream toe. The differences increase with $\phi$ and $Q_{p}$.

Depth-averaged velocities $v_{w}$ were evaluated along the weir crest ( $l$ coordinate) together with their components $v_{w p}$. These were related to their mean $v_{w p a}$ along the horizontal weir crest (Fig. 8). Note that the approximately constant $v_{w p}$ values at the central part of the horizontal weir crest section decrease at the toes of the inclined sections due to the higher hydraulic losses at those sections. This corresponds to the more significant changes in the flow direction at inclined sections, and to the more irregular flow there.

\section{Specific discharge along weir crest}

The measured $q_{p}$ along the weir crest was related to its mean value $q_{p a}$ expressed for the horizontal section of the weir crest (Fig. 9). For all $\phi$ and discharge scenarios, $q_{p}$ was almost constant along the horizontal weir crest; it was much smaller at inclined sections due to the smaller flow velocity and flow area at the sections.
The value of $q_{p}$ differs at the inclined up- and downstream weir edges (from $0.00 \mathrm{~m}$ to $0.40 \mathrm{~m}$ and from $1.90 \mathrm{~m}$ to $2.30 \mathrm{~m}$ ) (Fig. 8). The higher $\mathrm{Fr}_{u}$ and $\phi$, the more significant are the differences in $q_{p}$ over the weir crest. The flow regime at the inclined sections slightly propagates to the horizontal part of the weir crest to a distance of $2 h_{p}\left(\phi=60^{\circ}\right)$ to $3 h_{p}\left(\phi=90^{\circ}\right)$ from the toes of the inclined sections. This effect is the result of the water flowing from the inclined sections toward the horizontal section. At the upper edge $q_{p}$ is lower, while it is larger at the lower inclined edge.

\section{Discharge coefficients of horizontal and inclined sections}

First, the discharge coefficient $C_{D}$ for the horizontal section of the frontal weir was determined from Eq. (2) for $Q_{d}=0$. The obtained values of $C_{D}$ related to $h_{p} / t$ correspond with the values recommended by ISO 4362 (1999) and were in agreement with these of Fritz and Hager (1998); slightly lower values were provided by Tracy (1957) and rather overestimated values were derived by Goodarzi et al. (2012) for an upstream slope of 1:1.73 (Říha and Zachoval, 2014). Below the average derived value $C_{D}=0.971$ is used.

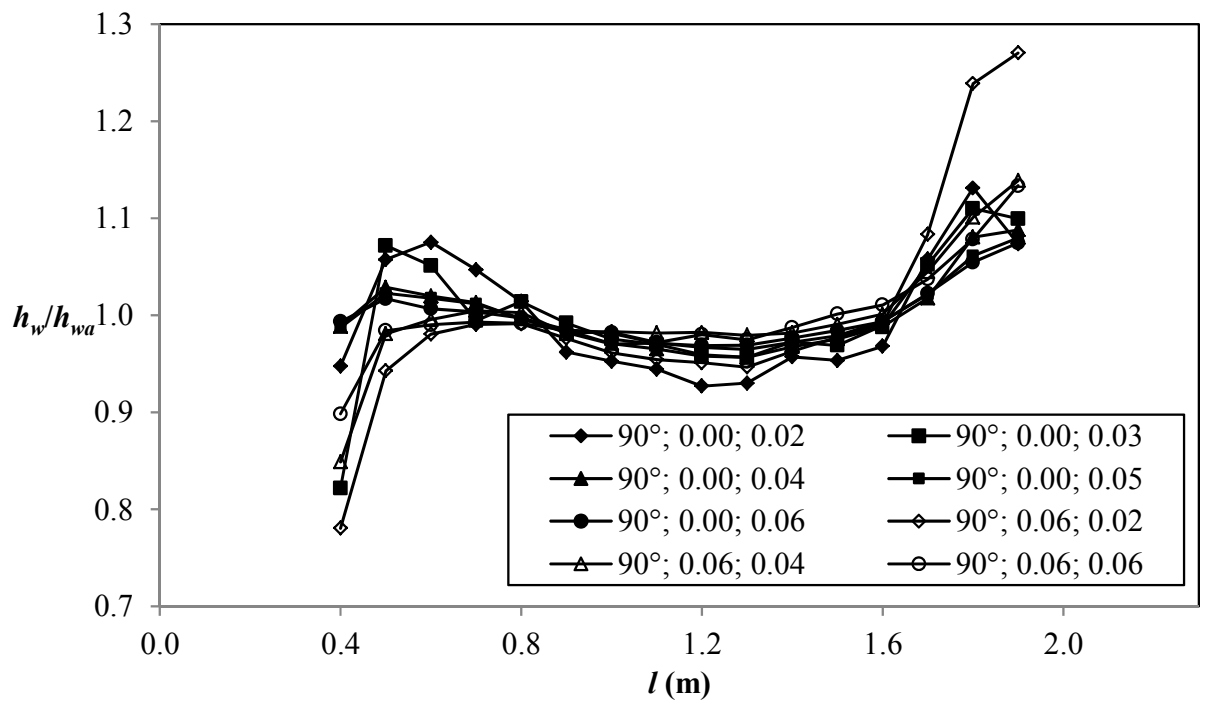

Fig. 5. $h_{w} / h_{w a}$ along weir crest axis for $\phi=90^{\circ}$ (legend: $\phi ; Q_{d} ; Q_{p}$ ).

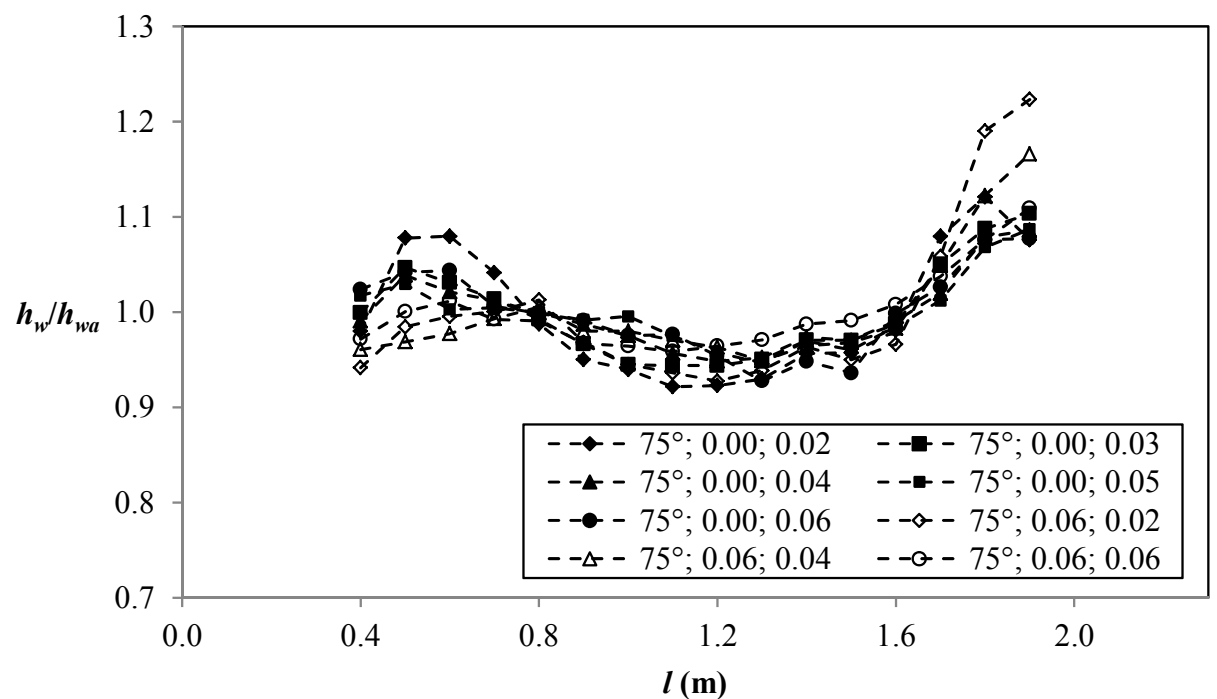

Fig. 6. $h_{w} / h_{w a}$ along weir crest axis for $\phi=75^{\circ}$ (legend: $\phi ; Q_{d} ; Q_{p}$ ). 


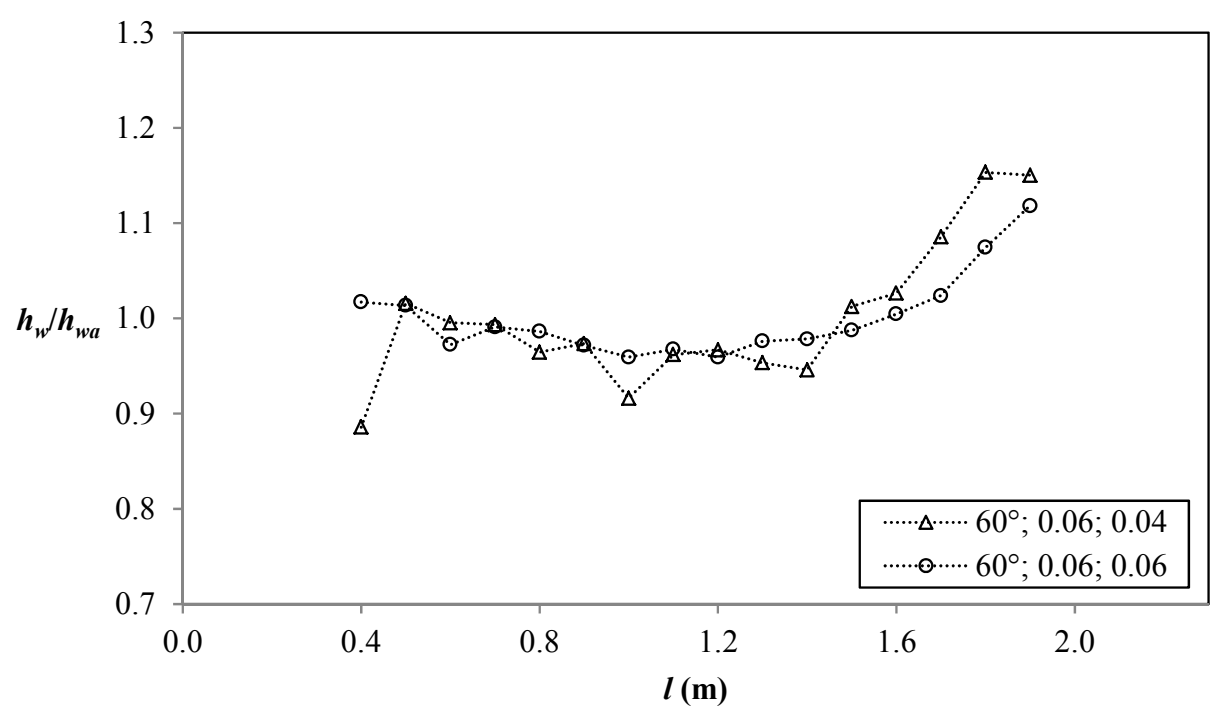

Fig. 7. $h_{w} / h_{w a}$ along weir crest axis for $\phi=60^{\circ}$ (legend: $\phi ; Q_{d} ; Q_{p}$ ).

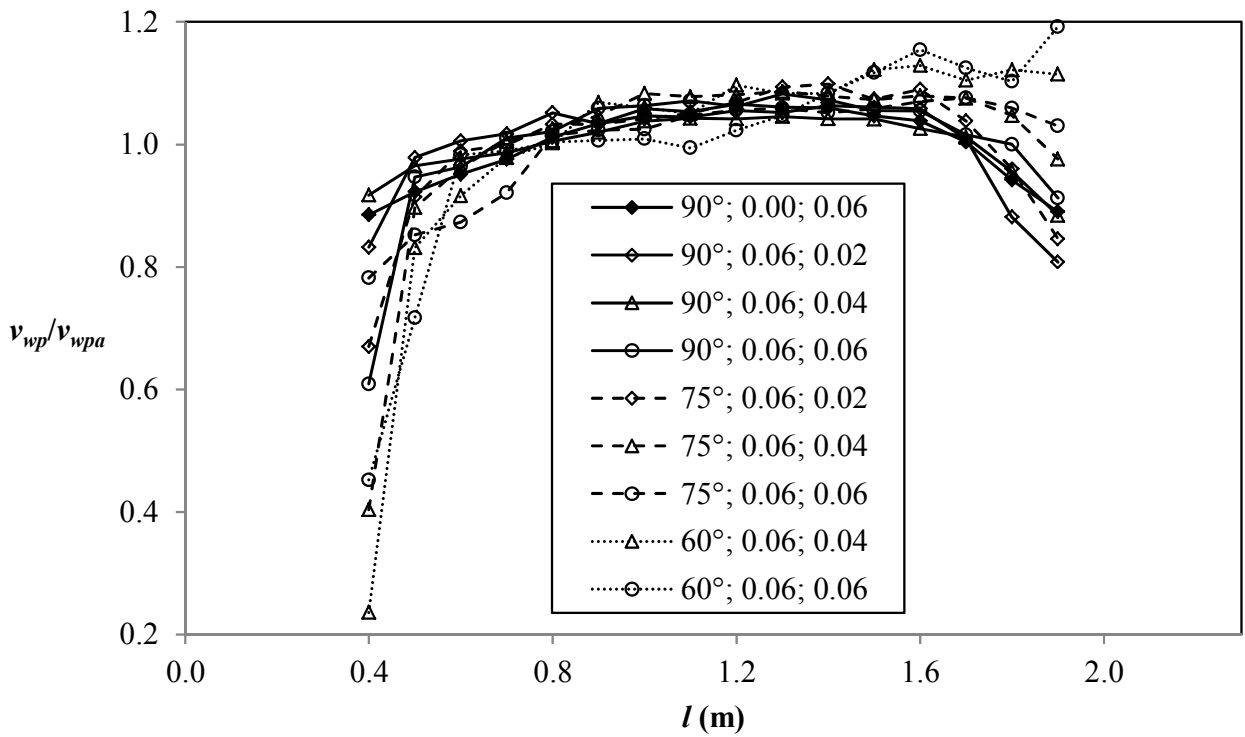

Fig. 8. $v_{w p} / v_{w p a}$ along weir crest axis (legend: $\phi ; Q_{d} ; Q_{p}$ ).

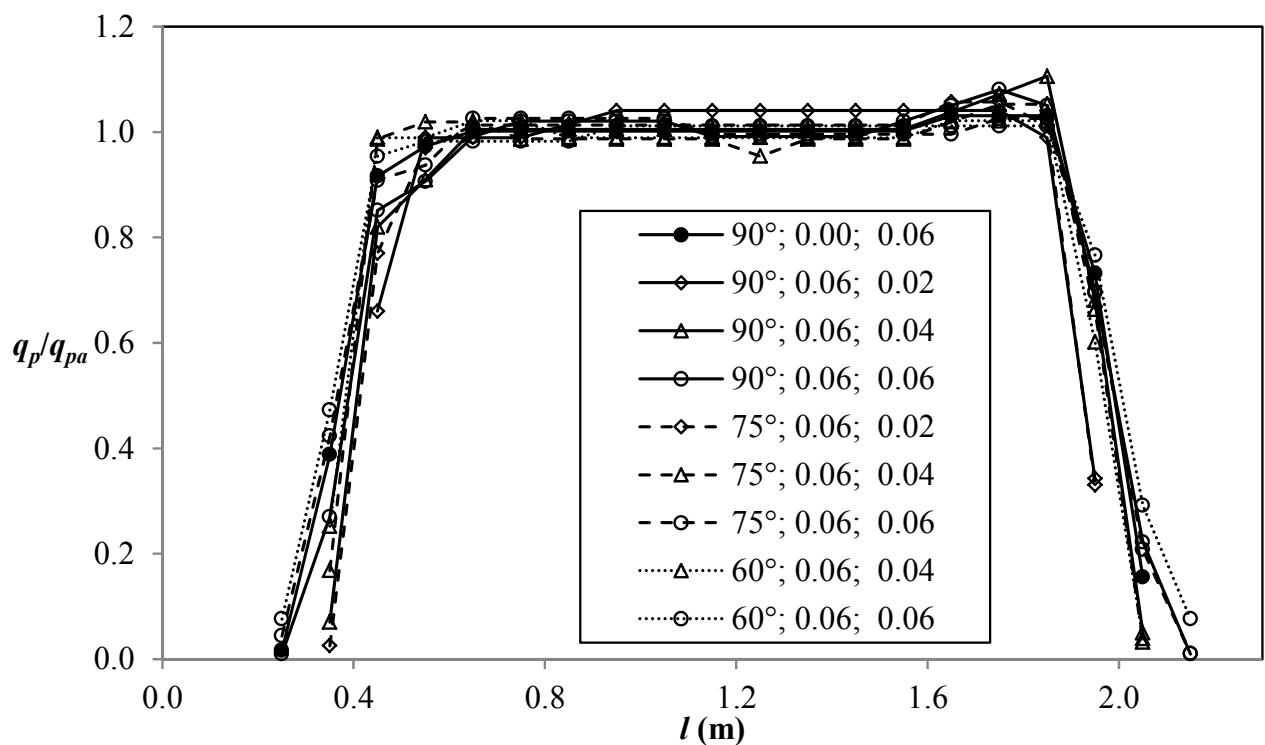

Fig. 9. Normalised specific discharge along weir crest for $Q_{d}=0.060 \mathrm{~m}^{3} \mathrm{~s}^{-1}$ (legend: $\phi, Q_{p} ; \mathrm{Fr}_{d} / \mathrm{Fr}_{u}$ ). 
For a known $C_{D}$ the coefficient of obliqueness $C_{\phi}$ for the horizontal section was derived from Eq. (2) using the experimental data. The correlation analysis proved the functional dependence (3) and showed the strong influence of parameters $\mathrm{Fr}_{d} / \mathrm{Fr}_{u}$ and $\cos \phi$ on $C_{\phi}$. When the influence of other parameters (e.g. geometry) frequently applied by various authors (Aghayari et al., 2009; Borghei et al., 1999; Emiroglu et al., 2011; Honar and Javan, 2007) was studied, they were found to be of much smaller importance. The resulting functional dependence is

$$
C_{\phi}=1+(0.16 \cos \phi-0.16) \frac{\mathrm{Fr}_{d}}{\mathrm{Fr}_{u}} \text {. }
$$

For the range $0.02<\mathrm{Fr}_{u}<0.12, \quad 0.25<\mathrm{Fr}_{d} / \mathrm{Fr}_{u}<1.5$, $60^{\circ} \leq \phi \leq 90^{\circ}$ and $b_{p}>6 h_{p}$ the coefficient of determination is $R^{2}=0.75$. The agreement between calculated and experimentally determined values of $C_{\phi}$ is shown in Fig. 10 . Note that practically all predicted values lie within $\pm 5 \%$. For practical applications, Bos (1989) recommends $C_{\phi}=0.95$ for $\phi=90^{\circ}$; in this case our measurements indicate a dependence on the $\mathrm{Fr}_{d} / \mathrm{Fr}_{u}$ ratio, because $C_{\phi}$ varies from 0.87 to 1.00 according to Eq. (5).

The discharge coefficient $C_{D T}$ was calculated from Eq. (2) using the measured values of $Q_{p T u}, Q_{p T d}$ and $h_{p}$, while taking into account the same $C_{\phi}$ as in Eq. (5). This assumption reflects the adopted concept of constant $C_{\phi}$ for horizontal and inclined sections of a trapezoidal weir crest. The resulting regression equation is $\left(R^{2}=0.77\right)$

$$
C_{D T}=0.71 \frac{h_{p}}{t}+0.05 \text {. }
$$

Due to the limited model size, only a relatively small number of measurements were conducted at inclined sections. A direct comparison of the obtained $C_{D T}$ with values derived by others is complicated by the lack of published data for similar weir layouts. The resulting values obtained for the combined coefficients $C_{D T} C_{\phi}$ were therefore compared with those obtained by Yahya (2011) for a V-shaped weir with an oblique angle of $\phi=90^{\circ}$ and a vertical upstream face. Yahya obtained values in the range of $0.2<C_{D T} C_{\phi}<0.4$, indicating good agreement with our data $0.25<C_{D T} C_{\phi}<0.4$. The differences in relevant $h_{p} / t$ are due to the different shape of the weir entrance (the vertical upstream face in the case of Yahya's research).

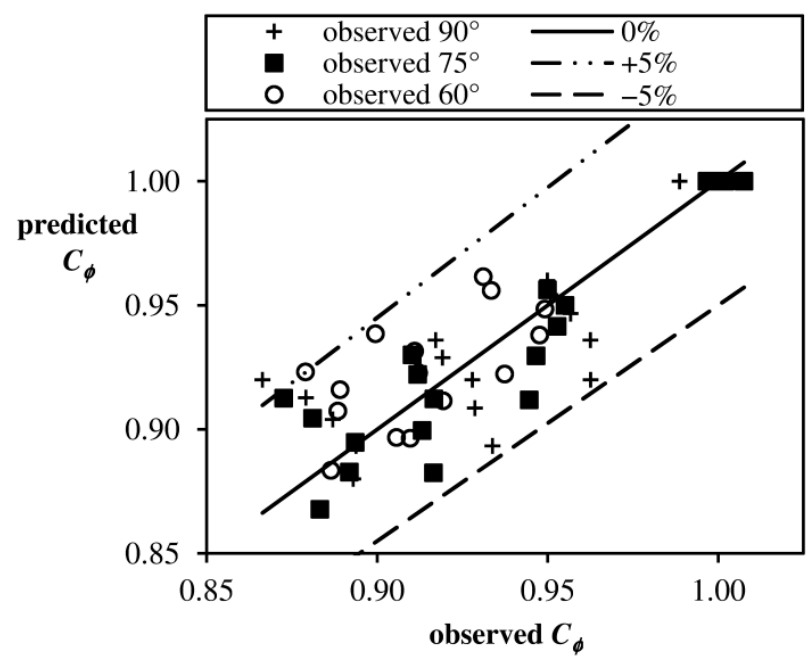

Fig. 10. Comparison of calculated and experimentally determined discharge coefficients $C_{\phi}$.

\section{CONCLUSIONS}

The extensive experimental research highlights the flow characteristics at the weir crest and in front of side weirs with different oblique angles $\left(60^{\circ} \leq \phi \leq 90^{\circ}\right)$ for various discharge scenarios $\left(0 \leq Q_{d} / Q_{p} \leq 3\right)$ at low Froude numbers $\left(0.02<\mathrm{Fr}_{u}<0.12,0.25<\mathrm{Fr}_{d} / \mathrm{Fr}_{u}<1.5\right)$. From the measured data the obliqueness coefficients $C_{\phi}$ and $C_{D T}$ were derived for inclined sections of a trapezoidal weir.

One of the most important findings was that $h_{p}$ and $q_{p}$ remains practically constant along the horizontal section of the weir at low Froude numbers $\left(\mathrm{Fr}_{u} \leq 0.12\right)$. The influence of inclined sections on the horizontal crest propagates to a distance ranging from $2 h_{p}\left(\phi=60^{\circ}\right)$ to $3 h_{p}\left(\phi=90^{\circ}\right)$ from the toes. As the inclined sections inversely influence the overflow at the horizontal section (see Fig. 9), the total effect can be neglected.

However, the magnitude and direction of angle $\delta$ of the velocity vector is not constant. The angle $\delta$ decreases along the weir crest towards the downstream weir edge. The angle $\delta$ is significantly influenced by the inclined edges of the trapezoidal weir. The water depth is lowest at the centre of the weir crest (Fig. 5 to Fig. 7), and the magnitude of the velocity component $v_{w p}$ perpendicular to the weir is at its maximum at this point (Fig. 8). For the central horizontal weir section $C_{\phi}$ depends on $\mathrm{Fr}_{d} / \mathrm{Fr}_{u}$ and on $\phi$ according to Eq. (5). A discussion on how the obtained results correspond with others is found in Section 5.

Acknowledgement. This study was supported by the Technological Agency of the Czech Republic, project code TA 04020670, and AdMaS UP - Advanced Materials, Structures and Technologies project LO1408.

\section{REFERENCES}

Aghayari, F., Honar, T., Keshavarzi, A., 2009. A study of spatial variation of discharge coefficient in broad-crested inclined side weirs. Irrig. and Drain., 58, 2, 246-254.

Borghei, S.M., Jalili, M.R., Ghodsian, M., 1999. Discharge coefficient for sharp-crested side weir in subcritical flow. J. Hydraul. Eng., 125, 10, 1051-1056.

Bos, M.G., 1989. Discharge measurement structures. ILRI, Wageningen, The Netherlands.

Castro-Orgaz, O., Hager, W.H., 2012. Subcritical side-weir flow at high lateral discharge. J. Hydraul. Eng., 138, 9, 777787.

De Marchi, G., 1934. Saggio di teoria del funzionamento degli stramazzi laterali, o sfioratori longitudinali (Essay on the performance of lateral weirs). L'Energia Electtrica, 11, 11, 849-860 (In Italian.)

Emiroglu, M.E., Agaccioglu, H., Kaya, N., 2011. Discharging capacity of rectangular side weirs in straight open channels. Flow Meas. Instrum., 22, 4, 319-330.

Frazer, W., 1957. The behaviour of side weirs in prismatic rectangular channels. Proc. Inst. Civil Eng. 6, 2, 305-328.

Fritz, H.M., Hager, W.H., 1998. Hydraulics of embankment weirs. J. Hydraul. Eng., 124, 9, 963-971.

Goodarzi, E., Farhoudi, J., Shokri, N., 2012. Flow characteristics of rectangular broad-crested weirs with sloped upstream face. J. Hydrol. Hydromech., 60, 2, 87-100.

Hager, W.H., 1987. Lateral outflow over side weirs. J. Hydraul. Eng., 113, 4, 491-504.

Honar, T., Javan, M., 2007. Discharge coefficient in oblique side weirs. Iran Agr. Res., 25, 2 and 26, 1-2. 
ISO 4362, 1999. Hydrometric determinations - Flow measurement in open channels using structures - Trapezoidal broad-crested weirs. Geneva, Switzerland.

ISO 8333, 1985. Liquid flow measurement in open channels by weirs and flumes. V-shaped broad-crested weirs. Geneva, Switzerland.

Kabiri-Samani, A., Ansari, A., Borghei, S.M., 2010. Hydraulic behaviour of flow over an oblique weir, J. Hydraul. Res., 48, 5, 669-673.

Novak, P., Čábelka, J., 1981. Models in hydraulic engineering. Physical principles and design applications. Pitman Publishing, Boston, USA, $459 \mathrm{p}$.

Ranga Raju, K.G., Prasad, B., Gupta, S.K., 1979. Side weir in rectangular channel. J. Hydraul. Division, ASCE, 105, 5, 547-554.

Ríha, J., Zachoval, Z., 2014. Discharge coefficient of a trapezoidal broad-crested side weir for low approach Froude numbers. J. Hydraul. Eng., 140, 8, 06014013.

Rosier, B., 2007. Interaction of side weir overflow with bedload transport and bed morphology in a channel. $\mathrm{PhD}$-thesis. École polytechnique fédérale de Lausanne, Lausanne, Switzerland.

Singh, R., Manivannan, D., Satyanarayana, T., 1994. Discharge coefficient of rectangular side weirs. J. Irrig. Drain. Eng., 120, 4, 814-819.

Stilmant, F., Pirotton, M., Archambeau, P., Roger, S., Erpicum, S., Dewals, B., 2013. Dike-break induced flows: a simplified model. Environ. Fluid Mech., 13, 1, 89-100.

Subramanya, K., Awasthy, S.C., 1972. Spatially varied flow over side-weirs. J. Hydraul. Division ASCE, 98, 1, 1-10.

Swamee, P.K., Pathak, S.K., All, M.S., 1994. Side-weir analysis using elementary discharge coefficient. J. Irrig. Drain. Eng., $120,4,742-755$.

Tracy, H.J., 1957. Discharge characteristics of broad-crested weirs. U.S. Dept. of Interior, Geological Survey, Circular 397, Washington, USA.

Yahya, A.A.A., 2011. Discharge coefficient for V-notch broad crested side weir. Al-Rafidain Eng., 19, 3, 104-111.

\section{NOTATION}

A

$b$

$b_{p}$

B

$C_{D}$

cross sectional area of channel

$\left(\mathrm{m}^{2}\right)$

bottom width of prismatic channel

(m)

weir width

(m)

width of water surface

(m)

discharge coefficient of frontal rectangular

broad-crested weir

$C_{D T}$

discharge coefficient of frontal V-shaped

broad-crested weir

$C_{v} \quad$ approach velocity coefficient

$(-)$

$(-)$

$C_{\phi} \quad$ weir obliqueness correction factor

Fr Froude number

$g$ gravitational acceleration

depth

$(-)$

$\left(\mathrm{m} / \mathrm{s}^{2}\right)$

(m)

overflow head

(m)

approach velocity head

$h_{w} \quad$ water depth along axis of horizontal weir crest (m)

$k_{s} \quad$ Nikuradse's equivalent sand roughness height $(\mathrm{m})$

$l \quad$ coordinate axis along weir crest $(\mathrm{m})$

$n \quad$ Manning roughness coefficient $\quad\left(\mathrm{s} / \mathrm{m}^{1 / 3}\right)$

$q_{p} \quad$ specific overflow $\quad\left(\mathrm{m}^{2} / \mathrm{s}\right)$

$Q \quad$ discharge in channel $\left(\mathrm{m}^{3} / \mathrm{s}\right)$

$Q_{p} \quad$ total overflow discharge $\left(\mathrm{m}^{3} / \mathrm{s}\right)$

$Q_{p p} \quad$ discharge over horizontal section of weir crest $\left(\mathrm{m}^{3} / \mathrm{s}\right)$

$Q_{p T} \quad$ discharge over inclined sections of weir crest $\left(\mathrm{m}^{3} / \mathrm{s}\right)$

$P \quad$ height of weir crest (m)

$R^{2} \quad$ coefficient of determination

$t \quad$ length of weir in direction of flow

$(-)$

depth-averaged velocity along axis of

$\begin{array}{ll}v_{w} & \text { depth-averaged velocity } \\ \text { horizontal weir crest }\end{array}$

$(\mathrm{m} / \mathrm{s})$

$v_{w p} \quad$ depth-averaged velocity component parallel with weir axis

coordinate axis along channel

$(\mathrm{m} / \mathrm{s})$

water level along channel axis

(m)

$x$
$Z_{h}$

$\delta$

flow angle at weir crest

(m)

notch angle

oblique angle

$\phi$

Subscripts

d downstream

upstream

average value

Note: Colour version of Figures can be found in the web version of this article. 